lisease of the brain; and the doctors would come to realise the still fragmentary character of their science, and to attach due importance to that maintenance of the universal in its conflicts with the individual will upon which trade, industry, art, and science depend. The recommendations of the commission would, in all likelihood, lead to such amendment of the law as would put an end to conflicts in courts of justice on questions of responsibility and disease.

\section{A CASE OF INTUSSUSCEPTION OF THE CAECUM, ASCENDING AND TRANSVERSE COLON, TREATED BY ABDOMINAL SECTION, WITH SUCCESS.}

BY ARTHUR E. J. BARKER, F.R.C.S., SURGEON TO CXITERSITY COLLEGE HOSPITAL AND TEACHER OF pRactical surgery at UNIVERSiTy college.

IN view of the comparative rarity of successful operations for intussusception I desire to place the following upon record. It appears to furnish additional evidence, if any is wanted, that abdominal section may be safely undertaken for this condition in its earlier stages even in young children, and ought, therefore, to be resorted to at once if other simpler methods of reduction fail.

Charles S-, aged four years, was admitted into University College Hospital on Aug. 25th, 1887. He had always been a healthy child, and had had no illnesses except measles and whooping-cough; he had been run over by a cab four months before, the wheel passing across his chest. His health had been excellent up to the day before admission; his bowels had been opened at 10 A.M., and he had gone to school and returned quite well. Nothing was noted up to bed-time, but at about 3 o'clock in the morning the child awoke, complaining of pain in the abdomen. $\mathrm{He}$ then passed a stool, which was fairly loose, but with no relief of the pain. A little later he tried to defecate, and brought away about a wineglassful of blood, and half an hour later some more. From this time on until 2 P.M., when I first saw him, he continued to lose blood from the rectum at short intervals. On admission, he lay with his legs drawn up and resisted examination. An ill-defined tumour could be felt in the left iliac fossa. The finger introduced into the rectum reached nothing abnormal at first, but was covered with blood and mucus on being withdrawn. When I examined the child his state was as above, but $I$ thought at one moment that I could reach a tumour in the bowel by the rectum. But even uncertainty on this point in no way influenced the diagnosis of intussusception of the large intestine, which appeared quite clear from the history, symptoms, and the presence of a hard tumour in the left iliac region. I therefore proceeded to distend the rectum and colon with water to as large an extent as appeared safe, and this seemed to have the effect of getting rid of the tumour as far as manual examination went. On my return, however, to see the patient at 7 P.M., $I$ found that he had continued in great pain, and to pass blood from the rectum, and that the tumour was as clearly present as before. I therefore decided at once to operate. All antiseptic precautions having been taken and chloroform having been given, I made an incision in the middle line from the umlilicus downwards for about $2 \frac{1}{2}$. The carbolic spray was only turned on a moment before the peritoneum was opened. On passing in my hand, I found the intussusception without difficulty in the left hypochondrium, but could not at first draw it into view. "The incision was therefore prolonged about an inch upwards to the left of the umbilicus, and I was then able to manipulate the mass within the abdomen, though with some difficulty. By drawing upon the intussuscipiens from below with the finger and thumb of one hand, and squeezing it upon the intussusceptum with the other finger and thumb, I was able to force the latter upwards and to the right, and gradually to unravel it (still within the abdomen). This was somewhat assisted by drawing upon the portion of bowel which ran into the intussusceptum from above, but was almost entirely accomplished by squeezing the latter from below and at the same time gathering in the slack in iny fingers. There was a little difficulty in reducing the last portion; but this was soon overcome ly steady pushing and drawing. The bowel was much congested and marked by submucous hæmorrhages, but was not very œdematous. When satisfied that the intussusception was perfectly reduced, some coils of protruded intestine were washed and the abdominal cavity mopped out with warm carbolised sponges, and closed in the usual way with seven or eight stout silk sutures. A dressing of salicylic wool was then applied after the wound had been dusted with iodoform, and the abdomen was firmly bandaged. The whole operation and dressing was finished within thirty-five minutes, and the patient bore it very well.

Immediately after the operation the child was given four minims of the tincture of opium, followed by two minims every two hours until the morning of the $27 \mathrm{th}$. On the day following the operation (26th) the child was sick four or five times, probably from the effect of the chloroform, but not afterwards. He was restricted to a milk diet, given in very small quantity. During the night of the 26th the bandage round the abdomen, which was very tight, was loosened a little, giving considerable relief, and on the 27 th I examined the wound and found it all that could be desired. The opium was then stopped and a little brandy was given with the milk. On the 28 th he was given a little chicken broth, and the bowels were moved naturally for the first time. As soon as the heaviness of the opium passed off he seemed very well. The wound was again examined and redressed on the 20 th, and looked perfectly satisfactory, and on the 31st he had a second stool naturally. He was then allowed to have some light solids. On Sept. 2nd the wound was dressed again and for the last time, the stitches being removed; a broad strapping of American plaster was put completely round the body to support the scar. After this there is nothing to note except that the child seemed quite well. During the first three days after the operation the temperature touched $101.2^{\circ}$ on two occasions, but was usually below $100^{\circ}$, and after the third day was always so until the patient was discharged on Sept. 16th quite well.

The operation was relatively a short one and was not very difficult. This was due to the fact that the method of unravelling the bowel by traction and squeezing from below, rather than by traction on the included bowel from above, was resorted to at once.

Having been more than once deceived by the disappearance of the tumour under inflation or injection into the belief that I had reduced an intussusception, I was quite prepared for a return of both tumour and symptoms in this case, and found little difficulty in making up my mind to adopt the only other means of saving the patient's lifenamely, abdominal section. The age of the patient added, perhaps, to the gravity of the procedure; but there was the hope that by operating early, while the child's strength was unimpaired and before serious structural changes had taken place in the bowel, the result would be quite different from that usually seen where abdominal section is under. taken. In this case the degree of strangulation or incarceration must have been very considerable, for blood was constantly being passed from the rectum, and when exposed by operation the bowel was seen to be deeply marked by ecchymoses. Nevertheless, the reduction of the intussusception offered no insuperable obstacles, the pressure of the mass between the fingers combined with traction on the intussuscipiens from below, probably unloading the vessels of the congested part, and so enabling it to slip up within a short time.

The few cases on record in which, like the present, an intussusception has been cured by abdominal section appear to me to open up a very large question. This has already been discussed by Mr. Hutchinson in his well-known classical paper published in the Transactions of the Medical and Chirurgical Society thirteen years ago, and by Mr. Marsh a little later, also by Mr. Howse conjointly with the late Dr. Hilton Fagge in a paper worthy of its authors. But it is a remarkable fact that in spite of the strong arguments in favour of this method of treatment of a very hopeless condition furnished by these gentlemen, and the three successful cases recorded by them together with one by Mr. Godlee, we have heard little or nothing of it within the last twelve years. As a matter of fact, there has not been, so far as $\mathbf{I}$ know, a single case of successful laparotomy for intussusception recorded in London during all these years, except Mr. Godlee's, until the present case. Now, what is the reason for this? Either intussuseeption is not such a common disease as formerly, and there has been no occasion at all to resort to severe methods of treating it; or some 
other method, safer and easier than laparotomy, has come into general use in the meanwhile; or, finally, laparotomy has proved itself a particularly dangerous procedure, especially in the case of young children.

Now I do not think it will be asserted that intnssusception is less common now than formerly. An appeal to our hospital records would show that just as many cases are admitted yearly as of old. And, as to the second proposition, I do not think that it has been shown that such great improvements in the methods of reduction of intussusception by inflation and injection have been introduced to the notice of the profession as to win its confidence and come into general use. I am aware that in Mr. Lund's apparatus for distending the lower bowcl we possess, perhaps, the most perfect appliance yet designed for the purpose; but I have yet to learn that it lias effected a revolution in the treatment of intussusception or removed the objections to the method of injection-viz., the danger of bursting the bowel, an accident which has frequently occurred. And as to the third question, whether laparotomy should be regarded as a hazardous procedure, especially in the young, experience is showing us every day that it has no special risks in the hands of careful surgeons, and that each day it is being simplified and improved. As to its propriety in the case of young children, in all of the successful cases above cited the age was below five years and the operation was well borne in three, although performed ander difficult circumstances in two cases.

I venture then once more to urge what has been so ably and elaborately pleaded in the papers to which I liave alluded--namely, that laparotomy offers a far more satisfactory and a safer means of treating intussusception than the methods hitherto in use, and has been shown by experience so far to have a strong claim upon the consideration of physicians and surgeons. Of course, no one would think of resorting to abdominal section until the milder means of inflation and injection had been given a fair trial. But just as in the case of hernix, we are prepared without hesitation and at once to resort to herniotomy on the failure of properly applied taxis, so, I venture to urge, we should be prepared at once, and without hesitation, to open the abdomen in those cases of intussusception which are not speedily reduced by injection or inflation. It may be objected that there are cases in which, when the abdomen has been opened, the condition will be found irreducible. This will only be true if the operation be undertaken late, and in such cases it is certain that injection could not effect reduction, and would most probably burst the bowel if persisted in. It has been demonstrated by Dr. Fagge and Mr. Howse that two very different conditions are met with in intussusception, one which has been called "incarceration," and the other "strangulation." In the first, which almost certainly runs into the second if neglected, reduction may be effected in every case by laparotomy, if the method of working from below upwards be adopted. But if the bowel by neglect has been allowed to run into the second stage-i.e., of strangulation, it is questionable whether any operative treatment, whether per anum or per abdomen, should be employed, at all events in children, whose powers by this time will be too exhausted for laparotomy, while inflation could do no good, and would probably lead to perforation.

I venture to think that this whole question of the treatment of intussusception is well worthy of the attention of the profession, and in bringing forward this case I have hoped pointedly to draw attention to it. I have hoped also once more to direct attention to those very valuable papers on the subject to which allusion has been made, and in which many of the points here only briefly referred to are handled in detail and in a masterly manner. The case now recorded serves but to emphasise the conclusions therein arrived at, and especially one which Mr. Hutchinson specially lays stress upon. He savs: "It is my impression

that in future operations the lower end of the invaginated tract ought always to be first sought, and that reduction oucht to be accomplished by squeezing it or pulling the sheath downwards, rather than by attempting to pull the contained tube ont. I am not at all sure that in some cases this might not be accomplished without bringing the parts into view. Shonld this not be found practicable, however, it is probable that the operator will find it much more easy in cases of intussusecption into the descending colon to bring the lower part into the wound than the upper one. It is the more necessary to draw attention to these points because they are both probably unlikely to occur of themselves to the operator's mind." In my own case the invaginated portion of gut could not be drawn out of the wound, and was entirely reduced within the abdomen by the method advocated by Mr. Hutchinson and just quoted.

(To be concluded.)

\section{THE SULPHUR SPRINGS OF GREAT BRITAIN} AND THEIR THERAPEUTIC ACTION.

BY WM. SQUIRE, M.D., F.R.C.P.,

PHYSICIAN TO THE ST. GEORGE, HANOVER-SQUARE, DISPENSARY.

AT this season of the year, when holiday plans are made with a view both to health and pleasure, it may be well to consider the advantages offered by our own mineral springs, and to compare them with those of various continental spas. Visits to different health resorts often prove beneficial by mere change of air, of scene, of society, amusements, or occupation; most so by suitability of the climate selected, and in some degree by the directly medicinal properties of their mineral waters. To these last qualities attention is now directed, and chiefly to the efficacy and mode of action of the sulphurous waters. Many of our more noted health resorts are serviceable to the residents and visitors more by their climate, elevation of site, freshness of air, and by the purity of the water than by any mineral impregnation of it. Malvern is a capital instance in all these points. They are to be found on the chalk hills around London, at Chagford in Devon, Hinckley in Leicestershire, Otley or Ilkley in Yorkshire, and many other places in the north of England, in Scotland, and in Wales. The above qualities add to the efficacy of the small amount of iron found at Tunbridge Wells, or at San Moritz; with other excitants they aid the somewhat stronger chalybeate at Spa. The action of the equally potent alkaline waters of Vichy and of Vals is modified by the mild climate (hot in summer) of Vichy, and the more bracing effect of the higher site of Vals. The slightly mineralised waters of Contrexéville and of Buxton owe much of their efficacy to the elevated position in which they are used, both places being at a similar height above the sea-level. Thermal baths in the summer, when too relaxing in sheltered or low-lying situations, can still be enjoyed at Plombières, 1310 feet above the level of the sea.

Impaired health is not limited to one season of the year, and though our means of restoration are restricted, yet suitable places for rest and treatment are always to be found. In winter days the more delicate patients return to the home fireside or seek sunshine on southern coasts; some less invalided sufferers can still benefit by the pure cold air of the more elevated or northerly stations, or join in the out-door exercises and amusements of Leamington or Cheltenham. The claims of our own country in these advantages are too often neglected ; the health resorts around us are remarkably varied, the benefits they offer are available at all seasons, and to all ; to reach them no distant separation from friends and home is involved, the fatigues of a long journey and the discomforts of crossing the sea are avoided. Our own mineral springs are as rich in medicinal properties and as varied as those most visited abroad. The bromo-iodides of the Woodhall Spa exceed the proportion yielded by the Kreuznach water. The thermal springs of Bath and the highly mineralised waters of Harrogate surpass those of Aix-la-Chapelle and Aix-les-Bains in the qualities for which they are famed. In sulphurous property the stronger Harrogate water exceeds the springs of Germany or Savoy; this is itself surpassed by that of Strathpeffer in Ross-shire; and this again by the Dinsdale sulphur spring.

For pure sulphur medication this source of Dinstale-onTees is unequalled by any sulphurous water source short of the $A l p s$ or Pyrenees. Thermal sulphur waters, if useful in airling some special remedial effects for which they are soucht, interfere with other desired objects of treatmont, partly by unduly exciting the circulation and increaning the action of the skin. On the other hand, any excess of saline ingredients in combination with sulphur may act unduly either as aperients or diureties. At Schinznach in Switzerland is a thermal sulphur water with $22 \mathrm{gr}$. of the sulphates of soda and of lime, $2 \mathrm{gr}$. of carbonates, $13 \mathrm{gr}$. of 